\title{
Doping Knowledge, Attitude and Practice of Pharmacists in Dessie, Northeast Ethiopia
}

\author{
Haftom Gebregergs Hailu (D) \\ Mengistie Yirsaw Gobezie (iD) ${ }^{2}$ \\ Abdu Tuha $\mathbb{D}^{2}$ \\ Ruth Mulugeta $^{2}$ \\ Solomon \\ Ahmed Mohammed (iD) ${ }^{2}$ \\ 'Department of Pharmacology and \\ Toxicology, School of Pharmacy, College \\ of Health Sciences, Mekelle University, \\ Mekelle, Ethiopia; ${ }^{2}$ Department of \\ Pharmacy, College of Medicine and \\ Health Sciences, Wollo University, \\ Dessie, Ethiopia
}

Background: Doping includes tampering, possession; trafficking; administration, assisting, encouraging, aiding, conspiring a prohibited substance, and an anti-doping rule violation. Doping in sports is increasing and diversifying involving physiological, mechanical, and pharmacological techniques and becoming a serious public health problem. Pharmacy professionals have a vital role in the fight against doping. This study assessed the knowledge, attitude, and practice of pharmacists on the use of doping agents by sportsmen and women. Methods: A community-based cross-sectional descriptive study was done targeting community pharmacists of Dessie city, Northeast Ethiopia. Structured questionnaires were distributed and collected between April and March of 2018. Data were analyzed using SPSS version 20.0. Linear regression was used and the level of statistical significance was set at a $p$-value $<0.05$.

Results: Of the 61 pharmacy professionals who participated in the study, 46 (75.4\%) were males and $15(24.6 \%)$ were females. Only $25(41.0 \%)$ and $13(21.3 \%)$ of the respondents said they watch and play sport regularly, respectively. The majority of the participants, 50 $(82 \%)$, supported the prohibition of performance-enhancing drugs in sport. The majority of the respondents, $55.7 \%$, agree that pharmacists are a potential source of doping agents. Only $27.9 \%$ of them mentioned World Anti-doping Agency (WADA) as the source of information about doping agents. Regarding identifying the WADA status of 13 agents, the average score out of 13 was 4.95 , while $80.3 \%$ of them scored less than or equal to seven. Factors associated with knowledge of participants were being male $(\beta=4.48, \mathrm{p}=0.02)$ and regularly watching sport $(\beta=2.64, \mathrm{p}=0.01)$.

Conclusion: Even though the pharmacists' low knowledge score revealed that they need further specialized training on doping and anti-doping, majority of them support banning doping substances from sport. Pharmacy curriculum developers should consider incorporating specific topics or courses about doping agents.

Keywords: doping, WADA, pharmacists, Ethiopia

\section{Introduction}

The term doping which is used to refer to the use of performance-enhancing drugs (PEDs) in sport is believed to be derived from the Dutch word "doop", meaning a viscous opium juice. ${ }^{1}$ Doping has probably existed in one or another form since the beginning of the competitive sport. ${ }^{2}$ World Anti-Doping Agency (WADA) defines doping as

The presence of a prohibited substance or its metabolites or markers in an athlete's bodily samples; use of a prohibited substance or method; tampering, providing fraudulent information to an anti-doping organization, possession of a prohibited
Correspondence: Solomon Ahmed Mohammed

Email ahmedsolomon2I@gmail.com 
substance or method; trafficking; administration of any prohibited substance or method; assisting, encouraging, aiding, abetting, conspiring, covering up or any other type of intentional complicity involving an anti-doping rule violation. ${ }^{3}$

The use of PEDs by sportsmen and women is banned for three main reasons: first the use of PEDs might be harmful to their health and well-being. ${ }^{4}$ Second, doping substances makes sports competitions unjust by giving an unethical advantage to those who use prohibited substances. Third, sportsmen and women are considered as role models within society and their use of PEDs could promote the consumption of such drugs by aspiring young athletes. 3,5

Doping in sports is increasing and diversifying involving physiological, mechanical, and pharmacological techniques and becoming a serious public health problem. ${ }^{6-8}$ It is present at both the professional and recreational levels. ${ }^{9}$ Even though millions of dollars are being thrown in advanced scientific researches, drug detection methods, doping control procedures, educational campaigns, policy advancements, and introducing strict penalties for those who are involved in doping, the use of PEDs shows no significant decrease in sport. ${ }^{6,10,11}$ The financial interests of athletes, coaches and their sponsors, the societal pressure to obtain better results, the media coverage of sports competitions and, the human nature might contribute to the abundant use of PEDs. ${ }^{7}$ This presents a difficult challenge for health professionals like physicians, pharmacists, and nutritionists, sports scientists and organizations, and society. ${ }^{10}$

Pharmacists in Qatar had a limited awareness of doping and anti-doping and achieved an average knowledge score of $53.2 \%$ regarding the prohibited status of drugs. ${ }^{12}$ Students' knowledge score regarding the prohibited status of drugs that may be used by athletes was around $50 \%$ in Qatar. ${ }^{13}$ Pharmacy students in Malaysia had a moderate level of knowledge (median score of $5 \pm 2$ ). They also had negative attitudes towards statements on doping in sports. $^{14}$

Healthcare professionals have a vital role in the fight against doping. ${ }^{10}$ Pharmacists can be the first port of call for athletes who require essential information on drug treatment or general health care. ${ }^{13}$ Pharmacists are professionals who have a comprehensive knowledge of the biochemical nature of drugs. ${ }^{10}$ The international pharmaceutical federation recognizes pharmacists as experts who play a crucial role in the deterrence of doping in sports. ${ }^{6}$ As a result, pharmacists should have adequate knowledge, expertise, communication skill, and awareness about doping to have a significant contribution to the prevention of illicit use of banned substances.

The purpose of this study was to assess the knowledge, attitude, and practice of pharmacists on the use of drugs and supplements by sportsmen and women. Despite previous reports were done in Pakistan ${ }^{10}$ and Qatar, ${ }^{15}$ an online literature search has revealed that no such study has been conducted in Ethiopia so far.

\section{Methodology}

\section{Study Area and Period}

A cross-sectional descriptive study was done from April and March of 2018 targeting community pharmacists of Dessie city, Northeast Ethiopia. The pharmacy professionals who were available and willing to participate during the study period were included in the survey. Dessie is located $450 \mathrm{~km}$ far from Addis Ababa, the capital city of Ethiopia.

\section{Study Design}

A community cross-sectional study design was used.

\section{Source and Study Population}

All pharmacy professionals (66) who were working in community pharmacies of Dessie city were the source population. Pharmacy professionals (61) who were agreed to participate were the study population.

\section{Inclusion Criteria}

Pharmacy professionals who were willing to participate in the study were included.

\section{Variables}

\section{Dependent Variable}

The dependent variable was the knowledge of pharmacy professionals on doping and anti-doping.

\section{Independent variables}

The independent variables were the socio-demographic characteristics of pharmacy professionals.

\section{Sample Size Determination and Sampling Procedure}

All Pharmacy professionals (66) who were working in community pharmacies and willing to participate were included. 


\section{Data Collection and Quality Assurance}

A structured self-administered questionnaire was employed to collect data. Structured questionnaires were distributed and collected between April and March of 2018. The structured questionnaires were designed to collect information on each of the key components of the study. The items in the questionnaire were compiled from the literature with some modifications. ${ }^{12,15}$

The contents of the questionnaires were divided into four parts. The first part contained questions about the demographic characteristics of the pharmacists such as gender, age, years of experience, college of study (private or governmental), their current qualifications, working institutions (private or governmental), and if they play and watch sport regularly.

The second types of questions were attitude and practice questions. The participants were asked to respond as yes or no. In the third category of questions, pharmacists were requested to rate their knowledge about topics like doping agents, masking agents, and medical exemption as poor, fair, good, and very good. Lastly, participants were appealed to identify if a list of 13 drugs were banned, not banned, or if they did not know the answer. The drugs were selected from the different specifics of the WADA list of prohibited substances provided that they were available on the local market at that time as proven by the first and last author at the time. The knowledge score of the pharmacists about the WADA status of the 13 compounds was compared with their demographic characteristics.

Data was collected by one druggist who had no working relation to the institutions after recruiting and half-day training with the supervision of the principal investigators. Pretest was carried out in five percent of the sample size at Kombolcha town. Completeness, accuracy, and consistency of data were checked immediately after collection, and confidentiality was maintained. The reliability of the questionnaire was also checked by Cronbach's alpha test $(74 \%)$.

\section{Data Management and Analysis}

Collected data were feed and analyzed using SPSS version 20.0 for Windows. The frequency and percentage of responses were produced and presented in tables. Linear regression was computed to test the association between participants' socio-demographic characteristics and knowledge on doping. The level of statistical significance for all tests was set at a $p$-value $<0.05$.

\section{Results}

\section{Pharmacy Professionals' Demographic Characteristics}

The response rate of the study was $92.42 \%$. Of the 61 pharmacy professionals who participated in the study, 46 (75.4\%) were males and $15(24.6 \%)$ were females. The average age of the participants was 30.6 years with 20 and 57 years becoming the youngest and oldest respectively. The years of experience of the pharmacists ranged from six months to 35 years with 6.7 years as the mean.

Regarding playing and watching sport, 25 (41.0\%) and $13(21.3 \%)$ of the respondents said they watch and play sport regularly respectively. The rest of the respondents, $36(59 \%)$ and $48(78.7 \%)$ said they do not watch and play sport regularly respectively (Table 1 ).

\section{Knowledge, Attitude, and Practice of Pharmacy Professionals on Doping and Anti-Doping Issues}

The majority of the professionals, $90.2 \%$, claimed that they did not receive any form of training on doping during their college studies. In addition to this, only $6.6 \%$ of them claimed that they had participated in workshops on doping

Table I Socio-Demographic Characteristics of Respondents $(n=6 I)$

\begin{tabular}{|c|c|c|c|}
\hline \multicolumn{2}{|l|}{ Variable } & \multirow{2}{*}{$\begin{array}{c}\text { Frequency } \\
18\end{array}$} & \multirow{2}{*}{$\begin{array}{c}\text { Percentage } \\
29.5\end{array}$} \\
\hline Age & $\leq 25$ & & \\
\hline & $>25$ & 43 & 70.5 \\
\hline \multirow[t]{2}{*}{ Gender } & Male & 46 & 75.4 \\
\hline & Female & 15 & 24.6 \\
\hline \multirow[t]{2}{*}{ Educational level } & Druggist & 33 & 54.1 \\
\hline & Pharmacist & 28 & 45.9 \\
\hline \multirow[t]{2}{*}{ Experience (years) } & $\leq 5$ & 27 & 44.3 \\
\hline & $>5$ & 34 & 55.7 \\
\hline \multirow[t]{2}{*}{ Working institution } & Private & 21 & 34.4 \\
\hline & Government & 40 & 65.6 \\
\hline \multirow{2}{*}{$\begin{array}{l}\text { Watching sport } \\
\text { regularly }\end{array}$} & Yes & 25 & 41.0 \\
\hline & No & 36 & 59.0 \\
\hline \multirow[t]{2}{*}{ Playing sport regularly } & Yes & 13 & 21.3 \\
\hline & No & 48 & 78.7 \\
\hline
\end{tabular}


in sport (Table 2). The majority of the respondents, $55.7 \%$, agreed that pharmacists are a potential source of doping agents (Table 3 ).

The participants were asked to rate their own knowledge on different issues related to doping as poor, fair, good, and very good. Only $3.3 \%$ of the participants rated their knowledge about doping agents and masking agents as good. Furthermore, only $11.5 \%$ of the respondents claimed that they had very good knowledge about prohibited methods of administration (Table 4).

The participants were also asked which source of information they would look at. Only $27.9 \%$ of them mentioned WADA while $42.6 \%$ of them claimed they would refer to the Food, Medicine, and Health Care Administration and Control Authority of Ethiopia (FMHACA)'s materials. The rest, 29.5\%, of participants said they would use both FMHACA and WADA documents. None of them had mentioned the International Pharmaceutical Federation (IPF).

In addition to their perceived knowledge on doping issues, the participants were also asked to identify the WADA status of 13 substances. Nearly two-thirds of pharmacy professionals reported that Pethidine and Cannabis were banned substances (Table 5). The average score out of 13 was 4.95 while $80.3 \%$ of them scored less than or equal to seven. The maximum score was 13 while the minimum was zero.

Gender and regular sports watching were found to have statistically significant associations with the knowledge of pharmacy professionals. Male participants $(\beta=4.48, \mathrm{p}=$ 0.02 ) were significantly more likely to have better knowledge compared to females. Participants who were regularly watching sport $(\beta=2.64, p=0.01)$ were more likely to have better knowledge than those who were not watching regularly (Table 6).

\section{Discussion}

The world anti-doping agency states, "It is the sportsmen/ women's duty to ensure that no prohibited substance enters his or her body". ${ }^{3}$ As pharmacists are in an irreplaceable position as drug experts to provide the much needed information about which drugs and nutritional supplements are safe for the athletes, the purpose of this study was to assess the knowledge, attitude, and practice of the community pharmacists towards doping and anti-doping.

In the year 2017, Martha Kelner of the British newspaper "The Guardian" had reported that the red blood cell boosting drug, erythropoietin, could be sold without

Table 2 Attitude and Practice of Pharmacy Professionals on Doping and Anti-Doping Issues ( $n=6 \mathrm{I}$ )

\begin{tabular}{|c|c|c|}
\hline Question & $\begin{array}{l}\text { Yes } \\
(\%)\end{array}$ & $\begin{array}{l}\text { No } \\
\text { (\%) }\end{array}$ \\
\hline Did you receive training regarding doping during your undergraduate studies? & 9.8 & 90.2 \\
\hline Have you completed any specific courses or workshops regarding doping outside of your "formal" training? & 6.6 & 93.4 \\
\hline Are you aware of any Ethiopian based resources and/or institutions available to help the fight against doping substances in sport? & 27.9 & 72.1 \\
\hline Do you possess a copy of the current list of substances prohibited in sport? & 19.7 & 78.7 \\
\hline Have you ever been consulted for advice on doping? & 21.3 & 78.7 \\
\hline $\begin{array}{l}\text { Have you ever felt that a medication you may have prescribed/dispensed for a legitimate reason might be used by an athlete to } \\
\text { improve sporting performance? }\end{array}$ & 18.0 & 82.0 \\
\hline Do you think it is acceptable for doctors to prescribe anabolic steroids for non-medical indications? & 18.0 & 82.0 \\
\hline Do you think nutritional supplements can be potential doping substances & 42.6 & 57.4 \\
\hline Do you think some substances might be banned only from specific sports & 41.0 & 59.0 \\
\hline Do you think some substances might be banned only during competition & 42.6 & 57.4 \\
\hline Do you feel that pharmacists have a role to play in the prevention of doping in sport? & 73.8 & 26.2 \\
\hline Do you feel that you are adequately trained for the prevention of doping in sport? & 36.1 & 63.9 \\
\hline Do you feel that you require further training regarding doping in sport? & 68.9 & 31.1 \\
\hline
\end{tabular}


Table 3 A Perceived Potential Source of Doping Agents to Sports Man/Woman by Pharmacy Professionals $(n=61)$

\begin{tabular}{|l|c|c|}
\hline Potential Source & Agree (\%) & Disagree (\%) \\
\hline Family members & 34.4 & 65.6 \\
\hline Team members/friends & 59.0 & 41.0 \\
\hline Doctors & 59.0 & 41.0 \\
\hline Pharmacists & 55.7 & 44.3 \\
\hline Drug dealers & 59.0 & 41.0 \\
\hline Sport scientists & 52.5 & 47.5 \\
\hline Internet & 60.7 & 39.3 \\
\hline Gym trainer/gym staff & 54.1 & 45.9 \\
\hline Veterinarian & 34.4 & 65.6 \\
\hline
\end{tabular}

Abbreviation: Gym, Gymnasium.

prescription in Addis Ababa, the capital city of Ethiopia. The reporter also claimed that one of the pharmacists knew the drug was a prescription-only drug and a WADA prohibited doping agent. ${ }^{16}$ However, had a pharmacist in Ethiopia sold a WADA prohibited agent to an athlete or anyone else, it would be the lack of knowledge and awareness that plays the most important role. In this study, the pharmacists were asked to identify the WADA status (banned, not banned or I do not know) of 13 locally available drugs. The average score was 4.95 out of 13 while $80.3 \%$ of them scored less than or equal to seven even though all of the substances were WADA prohibited. Nevertheless, $82 \%$ of the participants supported the prohibition of performance-enhancing drugs in sport. This might be due to a poor emphasis given to doping and anti-doping in the pharmacy education.

Similarly, the majority of the pharmacists, $72.1 \%$, did not know the availability of an Ethiopian institution that is tasked with fighting doping even though the Ethiopian anti-doping office has been in action since $2017 .{ }^{17}$ Most of them, $82.0 \%$, also believed that medications prescribed/ dispensed for legitimate reasons would not be used by an athlete to improve sporting performance. In addition to this, $82.0 \%$ of the participants responded that it is acceptable for doctors to prescribe anabolic steroids for nonmedical indications even though these agents are already banned by WADA. ${ }^{3}$ The above figures might be justified by the fact that $90.2 \%$ of the participants admitted that they did not receive any training on the role of drugs in sport during their college studies. Furthermore, $93.4 \%$ of them did not complete any specific courses or workshops on doping in sport outside of their "formal" training. The lower proportion might be attributed to the inability of medical institutions to incorporate a specific course or topic about doping and/or doping agents in their curriculum. It's also reported that there was a significant difference in the level of knowledge between respondents who did and did not attend courses on drugs in sport $(\mathrm{p}<$ 0.01). ${ }^{14}$ More education should be offered about doping for pharmacy students to promote anti-doping activities. ${ }^{18}$

The participants were asked which source they would consult if they were approached by a sportsman/woman who wants to check if their prescribed medication is banned or not. Only $27.9 \%$ of them mentioned WADA

Table 4 Knowledge of the Pharmacy Professionals on Different Doping Related Issues as Rated by Themselves $(n=6 \mathrm{I})$

\begin{tabular}{|c|c|c|c|c|}
\hline Question & $\begin{array}{c}\text { Poor } \\
(\%)\end{array}$ & $\begin{array}{l}\text { Fair } \\
\text { (\%) }\end{array}$ & $\begin{array}{c}\text { Good } \\
(\%)\end{array}$ & $\begin{array}{c}\text { Very Good } \\
\text { (\%) }\end{array}$ \\
\hline Doping agents & 44.3 & 27.9 & 24.6 & 3.3 \\
\hline Masking agents & 52.5 & 27.9 & 16.4 & 3.3 \\
\hline Sources of information addressing the prescription guidelines for sport man/woman & 42.6 & 29.5 & 19.7 & 8.2 \\
\hline Prohibited methods of administration & 44.3 & 23.0 & 21.3 & 11.5 \\
\hline Effects of doping agents on athletic performance & 24.6 & 32.8 & 23.0 & 19.7 \\
\hline Medical risks associated with the most commonly used doping agents & 41.0 & 26.2 & 21.3 & 11.5 \\
\hline Therapeutic Use Exemption & 50.8 & 19.7 & 21.3 & 8.2 \\
\hline $\begin{array}{l}\text { The restriction on the prescription of systemic corticosteroids before and during } \\
\text { competitive sport }\end{array}$ & 37.7 & 39.3 & 14.8 & 8.2 \\
\hline
\end{tabular}


Table 5 Knowledge of Pharmacy Professionals on That Drugs are Banned or Not $(n=6 I)$

\begin{tabular}{|l|c|c|c|}
\hline Drug's Name & $\begin{array}{c}\text { Banned } \\
\text { (\%) }\end{array}$ & $\begin{array}{c}\text { Not Banned } \\
\text { (\%) }\end{array}$ & $\begin{array}{c}\text { I Do Not Know } \\
\text { (\%) }\end{array}$ \\
\hline Mestrolone & 44.3 & 16.4 & 39.3 \\
\hline Erythropoietin & 41.0 & 27.9 & 31.1 \\
\hline Salbutamol & 23.0 & 52.5 & 24.6 \\
\hline Clomiphene & 24.6 & 37.7 & 37.7 \\
\hline Furosemide & 16.4 & 49.2 & 34.4 \\
\hline Cathinone & 57.4 & 14.8 & 27.9 \\
\hline Pethidine & 65.6 & 14.8 & 19.7 \\
\hline Cannabis & 65.6 & 14.8 & 19.7 \\
\hline Ephedrine & 39.3 & 36.1 & 24.6 \\
\hline Pseudoephedrine & 34.4 & 27.9 & 37.7 \\
\hline Prednisolone & 23.0 & 49.2 & 27.9 \\
\hline Insulin & 19.7 & 50.8 & 29.5 \\
\hline Propranolol & 39.3 & 39.3 & 21.3 \\
\hline
\end{tabular}

while $42.6 \%$ of them claimed FMHACA. However, there was neither a list of doping agents nor any information about doping on the official website of FMHACA as per June 2018 and August 2020. This showed that there is even a lack of awareness about where to find the right information about doping and doping substances.

Regarding nutritional supplements, only $42.6 \%$ of the participants think nutritional supplements can be potential doping substances. This is despite the fact that nutritional supplement consumption might contain possible contaminants and take above the recommended dose could lead to super physiological levels which could throw the athletes into trouble. ${ }^{19,20}$

The participants were also requested to rate their knowledge on some issues related to doping as poor, fair, good, and very good. Only two pharmacists had rated their knowledge about doping agents and masking agents as very good. The rest of the respondents rated their knowledge as fair, good, and very good. Many respondents, $44.3 \%$ and $52.5 \%$ of the respondents admitted their knowledge about doping agents and masking agents is poor respectively. This is in line with their poor knowledge when they were asked to identify a list of drugs from the WADA list if they were banned, not banned, and do not know. For example, $49.2 \%$ of the respondents said
Table 6 Socio-Demographic Factors Associated with Knowledge Score of Participants $(n=6 I)$

\begin{tabular}{|c|c|c|c|c|}
\hline \multicolumn{2}{|l|}{ Variable } & \multirow{2}{*}{$\begin{array}{c}\begin{array}{c}P \\
\text { value }\end{array} \\
0.56\end{array}$} & \multirow{2}{*}{$\begin{array}{c}\text { B } \\
-0.73\end{array}$} & \multirow{2}{*}{$\begin{array}{c}95 \% \mathrm{Cl} \\
-3.26,1.80\end{array}$} \\
\hline Age & $\leq 25$ & & & \\
\hline & $>25$ & & Ref & Ref \\
\hline \multirow[t]{2}{*}{ Gender } & Male & 0.02 & 4.48 & $\begin{array}{c}-4.73,- \\
0.35\end{array}$ \\
\hline & Female & & Ref & Ref \\
\hline \multirow[t]{2}{*}{ Educational level } & Druggist & 0.06 & 1.60 & $-0.07,3.28$ \\
\hline & Pharmacist & & Ref & Ref \\
\hline \multirow[t]{2}{*}{ Experience (years) } & $\leq 5$ & 0.31 & -0.14 & $-0.44,0.15$ \\
\hline & $>55$ & & Ref & Ref \\
\hline \multirow[t]{2}{*}{ Working institution } & $<$ I year & 0.09 & 1.31 & $-0.25,2.87$ \\
\hline & $<10$ year & & Ref & Ref \\
\hline \multirow{2}{*}{$\begin{array}{l}\text { Watching sport } \\
\text { regularly }\end{array}$} & Yes & 0.01 & 2.64 & $0.68,4.6 \mathrm{I}$ \\
\hline & No & & Ref & Ref \\
\hline \multirow[t]{2}{*}{ Playing sport regularly } & Yes & 0.05 & -2.40 & $-4.85,0.04$ \\
\hline & No & & Ref & Ref \\
\hline
\end{tabular}

Notes: $\beta$ is unadjusted, $n=61, R$ square $=53.0 \%$.

Abbreviation: Ref, reference category.

furosemide, a known masking agent, ${ }^{3}$ is not banned and $34.4 \%$ of them said they do not know if it is banned or not. The difference was due to the sample size and qualification of study participants.

Assessing their knowledge score on the WADA status of 13 doping substances, the participants' average score was 4.95 out of 13 while $80.3 \%$ of them scored less than or equal to seven. The maximum score was 13 while the minimum was zero. Such poor knowledge of pharmacists about the status of doping agents has also been reported in Qatar. ${ }^{12}$ This indicates there is an urgent need for education among pharmacy professionals about doping agents and anti-doping rules and regulations.

The present study revealed that gender and regular sports watch had a statistically significant association with knowledge of pharmacy professionals. Male participants and participants who were regularly watching sport were 4.48 and 2.64 times more likely to have better knowledge than females and those who were not watching sport regularly respectively. This might be attributed to males are very close to the sport and 
hence, have a better awareness. Thus, strengthening awareness could enhance community responsibility for doping prevention.

Despite a clear lack of knowledge among the participants about doping, the majority of them, 73.8\%), believe pharmacists have a role to play in the prevention of doping in sport. This combined with the interest of the majority of the respondents, $68.9 \%$, for further training about doping in sport; there is a hope for the future that pharmacists might provide the much needed information to sportsmen and women if trained appropriately. Evidence showed that few Ethiopian athletes were banned from international competitions after the WADA results from an investigation of proven doping allegations. Despite an increasing claim of doping, none of the medical schools in Ethiopia incorporate principles of doping in their curriculum. As this study is the first of its kind in Ethiopia, it might be used as an input to policymakers and baseline for further largescale studies.

Practical implication: Many supplements in pharmacies contain banned substances such as stimulants, hormones, and pro-hormones. Unless pharmacy professionals are aware of doping, athletes might consider these substances as a means of enhancing their performance. Athletes might knew little regarding the use, safety, and efficacy of performance-enhancing drugs and nutritional supplements. As a result, these substances should be regulated. Pharmacy professionals should promote the moral and ethical basis of sport and emphasize the long-term medical.

\section{Limitation of the Study}

The small sample size might not be extrapolated to the entire country. Moreover, social desirability bias was associated with the cross-sectional nature of the study.

\section{Conclusion}

Even though the pharmacists' low knowledge score revealed that they need further specialized training on doing and anti-doping, the majority of them supported banning doping substances from sport. Being male and regular sports watching had a statistically significant association with the knowledge of pharmacy professionals. Pharmacy curriculum developers should consider incorporating specific topics or courses. Doping control authorities' should also contemplate working with governmental institutions and organizations that represent pharmacists to improve the role of pharmacists on doping control.

\section{Data Sharing Statement}

The data used to generate this result are available from the corresponding author upon reasonable request.

\section{Ethics Approval}

This study was approved by the ethical committee of the department of pharmacy, college of medicine, and health sciences, Wollo University. The necessary explanation regarding the purpose of the study and its procedure, assurance of confidentiality, the right not to participate in the study without any consequences was done during questionnaire distribution. Only those who agreed had participated in the study. Confidentiality of the information obtained in the course of the study was ensured; no personal identifiers were used and data were analyzed in aggregates. All participants provided informed consent, and this study was conducted in accordance with the Declaration of Helsinki.

\section{Author Contributions}

All authors made a significant contribution to the work reported, whether that is in the conception, study design, execution, acquisition of data, analysis, and interpretation, or in all these areas; took part in drafting, revising, or critically reviewing the article; gave final approval of the version to be published; have agreed on the journal to which the article has been submitted; and agree to be accountable for all aspects of the work.

\section{Funding}

No funding has been received to conduct this study.

\section{Disclosure}

The authors declare no conflict of interests for this work.

\section{References}

1. Ambrose PJ. Drug use in sports: a veritable arena for pharmacists. $J$ Am Pharm Assoc. 2004;44(4):501-516. doi:10.1331/ 1544345041475698

2. Willick SE, Miller GD, Eichner D. The anti-doping movement. $P M R$. 2016;8(3):S125-S132. doi:10.1016/j.pmrj.2015.12.001

3. WADA. World Anti-Doping Code. Montreal: World Anti-Doping Agency; 2015.

4. Nieschlag E, Vorona E. Mechanisms in endocrinology: medical consequences of doping with anabolic androgenic steroids: effects on reproductive functions. Eur $J$ Endocrinol. 2015;173(2):R47-R58. doi:10.1530/EJE-15-0080

5. Holt RIG, Erotokritou-Mulligan I, Sönksen PH. The history of doping and growth hormone abuse in sport. Growth Horm IGF Res. 2009;19 (4):320-326. doi:10.1016/j.ghir.2009.04.009 
6. Khan N, Noushad S, Ahmed S. Sports pharmacy as an emerging health science field; a perspective on the global and national scope. Int J Endorsing Health Sci Res. 2018;6(1):58.

7. Vlad R, Hancu G, Popescu G, Lungu I. Doping in sports, a neverending story? Adv Pharm Bull. 2018;8(x):1-8.

8. Tandon S, Bowers LD, Fedoruk MN. Treating the elite athlete: antidoping information for the health professional. Mo Med. 2015;112 (2):122-128.

9. Lentillon-Kaestner V, Carstairs C. Doping use among young elite cyclists: a qualitative psychosociological approach. Scand J Med Sci Sport. 2010;20(2):336-345. doi:10.1111/j.16000838.2009.00885.x

10. Ali A, Ansari M, Khaliq A, Jhatia A, Bhutto G, Mahesar H. Measuring the perceptions of pharmacy students of doping prevention: Case Study of a Pakistani Universities. SIND Univ Res J. 2016;48(4):761-767.

11. Erickson K, Backhouse SH, Carless D. 'I don't know if I would report them': student-athletes' thoughts, feelings and anticipated behaviours on blowing the whistle on doping in sport. Psychol Sport Exerc. 2017;30:45-54. doi:10.1016/j.psychsport.2017.01.005

12. Mottram D, Khalifa S, Alemrayat B, et al. Perspective of pharmacists in Qatar regarding doping and anti-doping in sports. J Sports Med Phys Fitness. 2015;56(6):817-824.

13. Awaisu A, Mottram D, Rahhal A, et al. Knowledge and perceptions of pharmacy students in Qatar on anti-doping in sports and on sports pharmacy in undergraduate curricula. Am J Pharm Educ. 2015;79 (8):119. doi:10.5688/ajpe798119
14. Chan SY, Lim MC, Shamsuddin AF, Tuan Mahmood TM. Knowledge, attitude and perception of Malaysian pharmacy students towards doping in sports. J Pharm Pract Res. 2019;49(2):135-141. doi:10.1002/jppr.1478

15. Laure P, Binsinger C, Lecerf T. General practitioners and doping in sport: attitudes and experience - commentary. $\mathrm{Br} J$ Sports Med. 2003;37:335-338. doi:10.1136/bjsm.37.4.335

16. Kelner M. Inside the doping hotspot of Ethiopia: dodgy testing and EPO over the counter. Theguardian. 2017. Available from: https:// www.theguardian.com/sport/2017/aug/04/doping-hotspot-ethiopiadrug-testing-epo. Accessed May, 2019.

17. ENDAO. Ethiopian national anti-doping office. Available from: https:/ethnado.org/2018/02/06/our-vision/. Accessed March, 2020.

18. Whitaker L, Backhouse S, Long J. Reporting doping in sport: national level athletes' perceptions of their role in doping prevention. Scand J Med Sci Sports. 2014;24(6):e515-21. doi:10.1111/sms. 12222

19. Suzic Lazic J, Dikic N, Radivojevic N, et al. Dietary supplements and medications in elite sport - polypharmacy or real need? Scand J Med Sci Sport. 2011;21(2):260-267. doi:10.1111/j.1600-0838.2009.01026.x

20. Van Thuyne W, Van Eenoo P, Delbeke FT. Nutritional supplements: prevalence of use and contamination with doping agents. Nutr Res Rev. 2006;19(1):147-158. doi:10.1079/NRR2006122
Integrated Pharmacy Research and Practice

\section{Publish your work in this journal}

Integrated Pharmacy Research and Practice is an international, peerreviewed, open access, online journal, publishing original research, reports, reviews and commentaries on all areas of academic and professional pharmacy practice. This journal aims to represent the academic output of pharmacists and pharmacy practice with particular focus on integrated care. All papers are carefully peer reviewed

\section{Dovepress}

to ensure the highest standards as well as ensuring that we are informing and stimulating pharmaceutical professionals. The manuscript management system is completely online and includes a very quick and fair peer-review system, which is all easy to use. Visit http://www.dovepress.com/testimonials.php to read real quotes from published authors. 